\title{
Valuating Hydrocarbon Pipeline Facility Service Beyond 20-25 Year Economic Life: Accounting for Residual Value
}

\author{
C. E. Alaneme*, S. N. Al-Lajam, A. A. Al-Jaafari, S. B. Al-Otaibi \\ Pipelines Distribution \& Terminals Division, Facilities Planning Department, Saudi Aramco, SAUDI ARABIA.
}

\begin{abstract}
The 20-25 years economic life for hydrocarbon pipelines in the investment decision model is at wide variance with historical statistical records of more than 90-percent world-wide. Opinions diverge, from service type to the product quality, and materials resilience as basis for this premise. While, financial experts consider time to fully depreciate a capital investment, irrespective of the rate of returns, engineers consider operational availability and reliability duration. The risk is that actual residue values of pipelines worldwide are erroneously omitted in every project's economics Cash-flow computation, thus eroding the investment decision quality. Statistics showed that more than 60-percent of pipelines worldwide have already exceeded the 25 years economic life, while more than 40-percent have operated more than 30-years and above. This theoretical appraisal identified a gap in the economic model in handling multi-criteria risk management uncertainties like hedging, weighting, etc., and highlighted the exigency to craft and assign numeric residue values for pipelines in the investment Cash-flow models.
\end{abstract}

Keywords: economic life, investment decision, life cycle cost, pipelines, project profitability, residual life

\section{INTRODUCTION}

Virtually every oil and gas exploration and production process require the transportation of different grades of hydrocarbon fluid including; crude oil, gas, and refined petroleum products from one operational point to another, through pipelines, as schematically shown in Fig. 1.

The hydrocarbon pipelines, such as depicted in Fig. 2, constitute a major artery in the oil and gas hydrocarbon exploration and production business, ranging in diameter from 4-inches (101.6 millimeters) to 56-inches (1,422.4 millimeters) and above, and in length, from less than one kilometer to 8,707 kilometers, being the longest pipeline in the world [1] ever constructed. Investment in oil and gas pipeline facilities is quite substantial, considering the magnitude of metric tons of steel required and given an average wall thickness of the pipelines that ranges from minimal 0.24-inches (6-millimeters) to 0.98-inches (25-millimeters) on average and above. This is apart from the associated engineering, procurement, construction, and operating costs, apart from maintenance and other recapitalization costs.

Primarily, investments in oil and gas hydrocarbon transporting pipelines, for most operating companies worldwide, are premised on a 20 to 25

\footnotetext{
${ }^{*}$ Corresponding author (Tel: +966 542019 317)

Email addresses: alaneme@yahoo.co.uk (C. E. Alaneme), saleh.lajam@aramco.com (S. N. Al-Lajam), ahmed.jafery@aramco.com (A. A. Al-Jaafari), salman.otaibi.4@aramco.com (S. B. Al-Otaibi)
}

years' service life [2, 3]. This applies to pipelines installed either above ground as in Fig. 2 or installed underground as in Fig. 3. This implies that the pipeline facilities will economically remain of value only within that set economic life precinct and will be reset to zero value at the expiration of the specified "magic" life. Conversely, experience shows that the basis of oil and gas pipelines economics grossly undermines the real economic value of this facility to a point of creating uncertainties on when to abandon or discard an active pipeline. The usual muted thinking is, what happens to the pipeline assets thereafter; abandon, mothball, or retain in service? Some pipeline projects, especially for sweet sales gas and natural gas liquid, hardly scale through the economics decision threshold or huddle rate, basically on practices that may have been skewed or are at best, inaccurate.

In reality, despite increasing water cuts in the crude oil pipelines, due to aging fields, and which will remain a recurring challenge as the pipelines also get much older, more than 40 percent of the hydrocarbon pipelines worldwide are statistically more than 30 years old [4, 5], as depicted in Fig. 4, despite operating under adverse conditions. Interestingly, some of the pipeline projects barely scaled through the economics hurdle at options selection stage, especially the pipelines in sales gas and natural gas liquid services. These investment durations were without recognizing the positive residual value. The extended duration needs to be recognized and factored in the eco- 


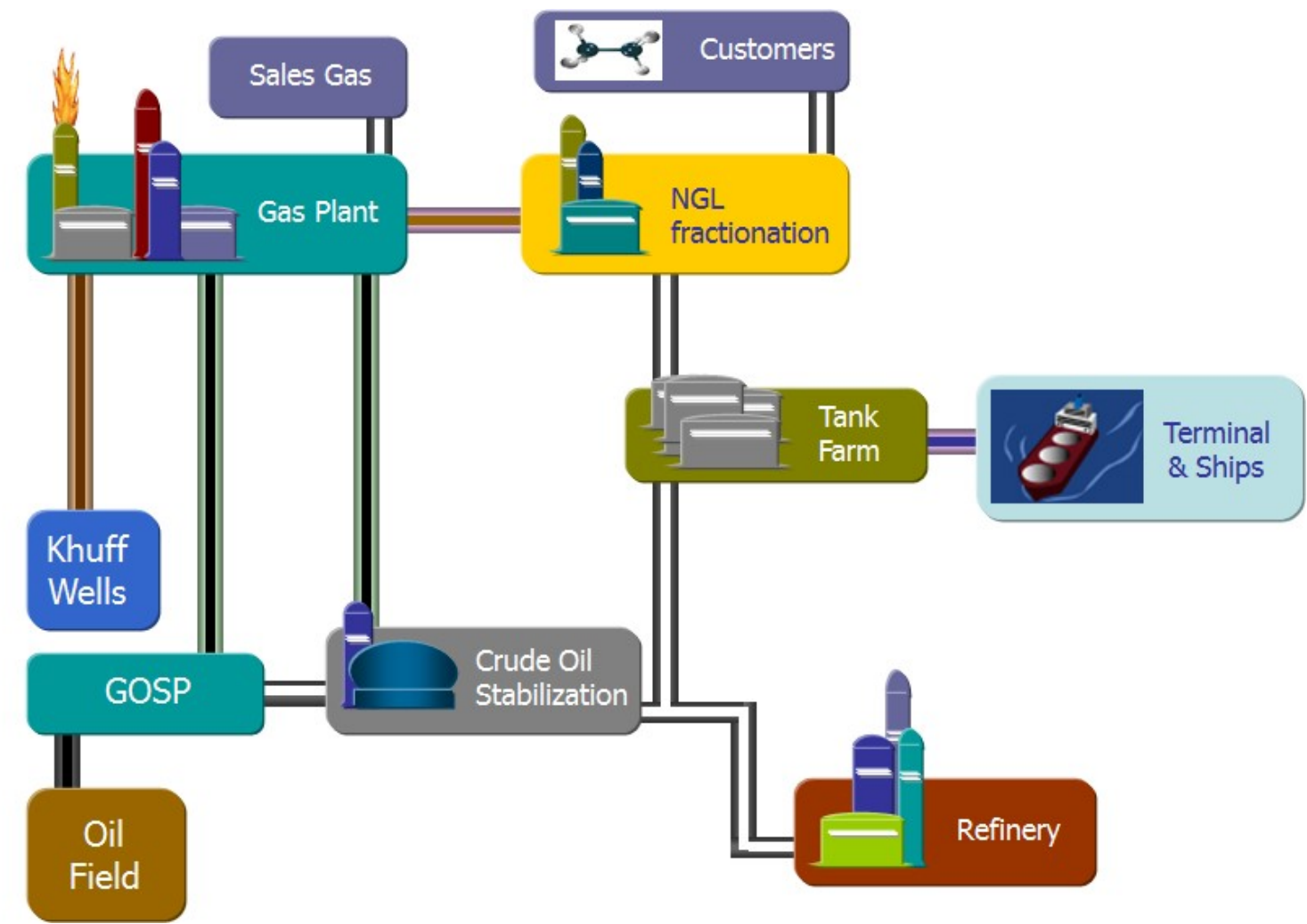

Figure 1: Pipelines connecting hydrocarbon basic operations. Source: Author's research.

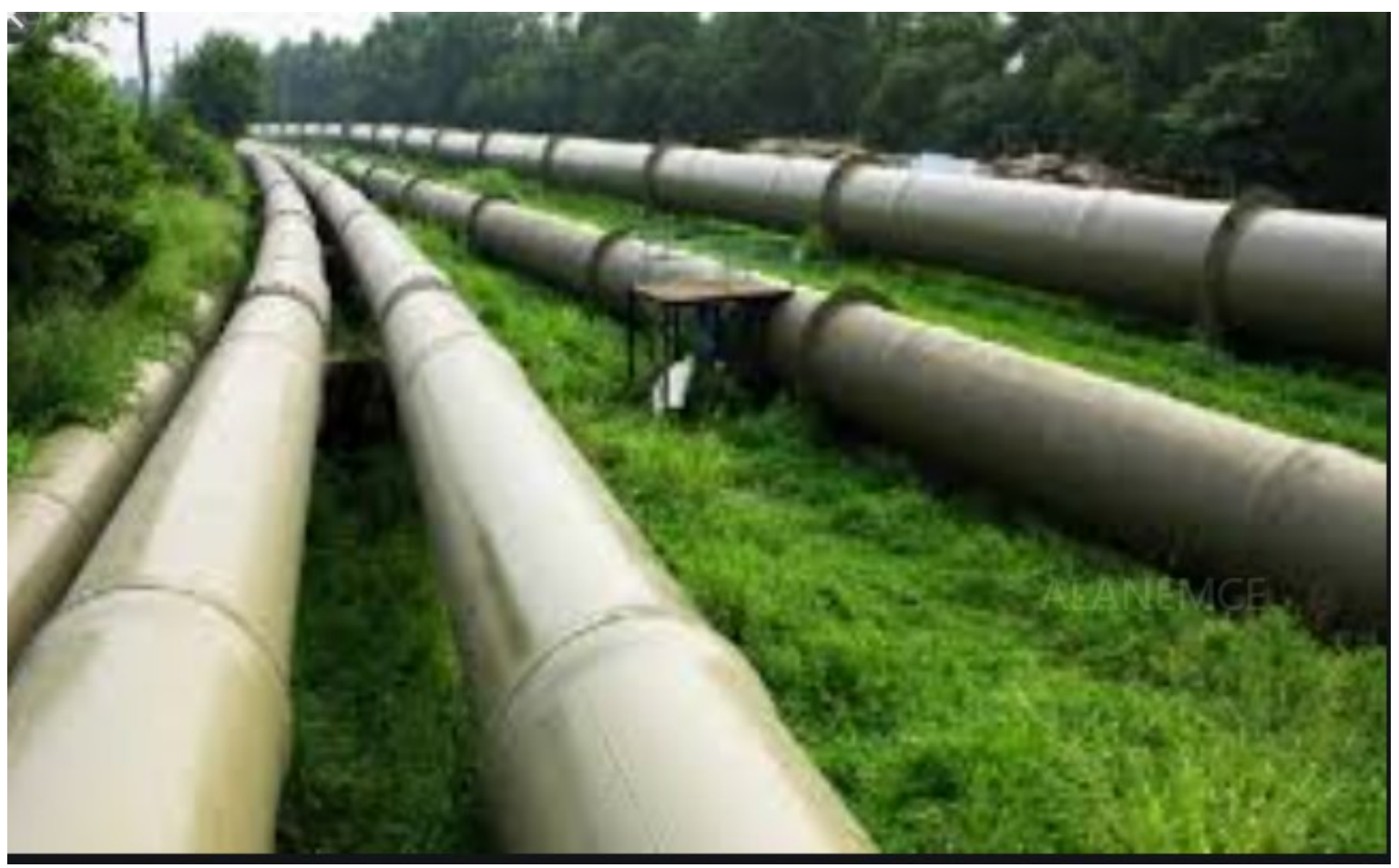

Figure 2: Above ground pipelines operating in Nigeria. Source: Nairametrics, January 2020. 


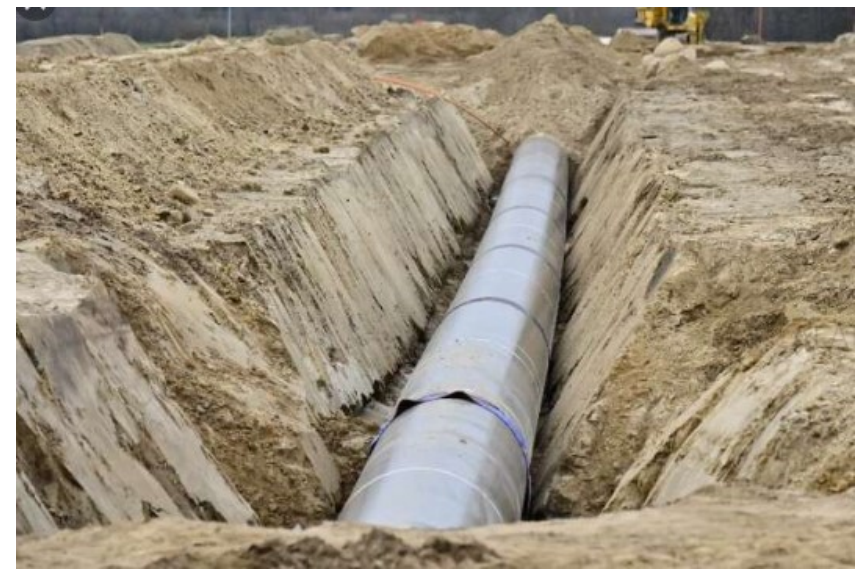

Figure 3: Pipelines buried underground. Source: Author's research.

nomics cash-flow model. This situation, without the pipeline facilities full asset value undoubtedly, leads to rash, skewed, and error-laced investment decisions.

Based on findings from oil and gas major operating companies worldwide, most organizations have pipelines in their inventory that have been in operation for more than 60 years, and still operating, without manifesting significant integrity degradation or any reasonable statistical recorded failures. In the same study, statistics also showed that pipelines that were retired before their economics life span, on basis of reliability failure or constraints, fall below the five percentile worldwide [6], while more than ninety-five percent have operated more than the designed $20-25$ years. Paradoxically, the 20-25 year life generally in practice is merely an axiom [7], and grossly at huge variance with historical reality, masking an irregularity that undercuts the total functional values of pipeline assets. In principle, this service life duration philosophy is mostly an arithmetically driven consideration based on principles of economics model limitations rather than actual historical performance or operationally tested parameters. How to monetize or plough back the residual value of pipeline assets to reflect the remaining life-after-economics span in the investment cash-flow model remains an enigma. First, the mechanism for deciphering, crafting a relationship, and factoring the residue value of pipelines in the economics cash-flow model needs to be conceptualized.

While the operational lifespan of a pipeline is economically determined by convenience, most organizations depend on statistical referencing of the technical fitness to decide the actual end life [6]. The concern is how the residual values positively influences investment decisions for new pipeline projects at economics threshold values. Incidentally, time value of money remains the common denominator in determining project's choice and viability, among alternatives [2]. Investment decisions continue to center on cash-flow net present value summation [2], where revenues pay off the capital expenditure, the operational costs or controllable costs, royalty payment as applicable, and taxes. Conspicuously missing in the cash-flow relation model is a risk factor to refine the outcome [8]. In addition, while significant investments in routine asset sustenance, which is factored in the economics model as operational and maintenance costs, or controllable costs in some parlance, a missing factor is the substantial investment in recapitalization that come in different forms of sectional replacements, upgrades, etc.

The import is that the 20 to 25 years used to define the economic lives of pipelines, lacks adequate statistical support and falls enormously short of verifiable total functional span for virtually all organizations. This equally portends a futuristic risk when deciding the asset book value and when to abandon, or the truism of its actual life.

\section{PIPELINE INVESTMENTS PROFITABILITY INDICATORS USING CASH-FLOW MOD- ELS}

Given that the value of a pipeline project relates to its potential to remain in service to continuously support the generation of cash, the total at-service value stretches beyond the 20-25 economics life to, as long as the time to total failure - often more than 60-years. A simplistic economics model merely uses a cumulative cash-in and cash-out flow indicators for the pipeline investment. Given that this is a mere averaging of earnings against cash injections discounted over a period, the discounted period becomes a major source of uncertainty, which could make or mar a project profitability or preference. Although the profitability cash-flow, in its entirety, excludes financing costs, the cash-flow model is erroneously assumed to have included all discrete factors with potential positive or negative impact, including taxes and abstract factors like inflation. The total at-service life of pipeline facilities becomes a game changer in providing a realistic basis of comparison and basis for options evaluation. The challenge is to establish a mechanism for establishing the economic limit or the total at-service life of a pipeline, through estimating the residual life value after the economic lives.

The generally deduced profit relation shows a very simplistic net cash flow relation without vividly accounting for the effect of risk [9], nor does it account for the respective assets' residue values. Without the associated risk or the asset residual values, the profitability relations simply provide only a feel-good estimate and not a true investment viability, which in reality, could swing either upwards or downwards from the ideal return on investment. Simply put and for business perspective, evaluating the investment efficiency starts from the options evaluation and decision criteria, with each option considered on the entire life cycle. This requires a full knowledge of the return on average capital employed (ROCE), and 


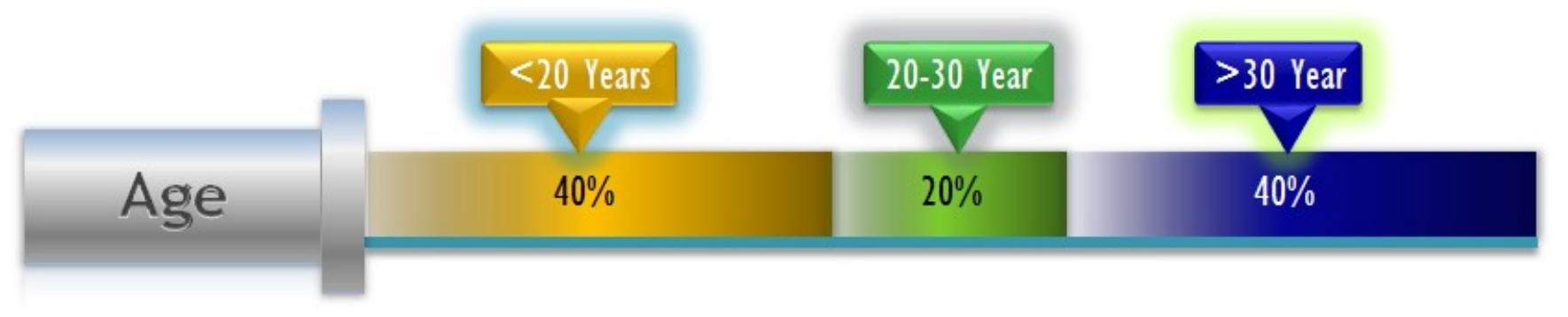

Figure 4: Worldwide pipeline age statistics. Source: Author's research.

entails infinite analysis of the true value of the assets that centers on its extractable services, from design to complete abandonment, over the total capital and operational cost exposures. Leaving us with the obvious question: in targeting the difference between the net income and total financial costs to arrive at the ROCE, how significant is the omitted difference in extractable services between the true life-duration and the economic life? The cash-flow tripod model apparently is hinged on two opposing factors whose outcome decides the economic viability factor; the Expenditure that is offset by the Revenue.

\section{EXPENDITURE FUNCTION}

Expenditures basically refers to amounts of cash invested in the form of disbursed capital and operational expenses. Capital expenditure factor constitute the major cost factor in the cash-flow model for determining the profitability of an investment. The cost includes the initial investment and recapitalized maintenance or costs expended in sustaining the asset capital value within the economics value. Such value includes costs for asset sectional replacement or upgrade, asset integrity validation such as in line inspection, and others. Typically, this cost covers design, construction of new facilities; installation costs of new equipment prior to hand over to operations. Unlike the capital investments which are gradually deducted or expensed through depreciation, depletion, or amortization, the operational expenses are deducted from income within the accounting period to arrive at the net income. This includes applicable pro-rates for the allocation of overhead costs of required support services and activities; the capital required to maintain operations through the life of the project or sustaining capital. It also includes the working capital and inventory costs; the value of existing equipment transferred for use in the project; a salvage value of the capital equipment and physical plant at the end of the project life. Of significance and which should not be confused with residual at-service value is the salvage value, which is merely the book value of a physical asset at the time of abandonment. The book value is tailored to document the remaining value out of the $20-25$ years eco- nomic life, based on the discounted rate to derive the remaining value.

\section{REVENUE BASED ON EXPECTED VALUE METHOD AND NET PRESENT VALUE}

The expected value concept would have offered an opportunity to capture assets residual value that could be ploughed back into future valuation as a risk factor. This could only work out, provided the organizational culture supported the estimation and quantification of the associated residual value of the respective assets. The risk factor should be collated continuously over time with the expected opportunity values, through an extricated probability function based on historical summation. The existing formula targeted only an unbiased single point estimate by collapsing a probability distribution into a single value number $[2,10]$. The Present Value, (PV) function as represented in Eq. (1), is a generally recommended value measure for expected monetary value (EMV), used by hydrocarbon field operators without a plough back of residual values in decision making, to associate the profitability,

$$
P V=C F \frac{1}{(1+i)^{-t}}
$$

Where discount rate, $i$ is the decision maker's attitude toward the time value of money, $C F$ is cashflow amount (future value) at time in years.

Again, this present concept works on the premise that earned money may be re-invested at a certain amount of interest, or put into a savings account at a profitability of say $15 \%$, the applied percentage, also called the "discount rate", "hurdle rate" or "cutoff rate" [11].

The present value concept is also similar in application to that of real time (RT) money, a time dependent value of money, where it is widely used in the economic evaluation of field development at inception This is also used to evaluate the cost of exploration programs, and discretely calculated simply in Eq. (2) as undiscounted futuristic amount [12]:

$$
X_{P V}=\frac{X}{(1+d)^{n}}
$$


Where $X$ is the undiscounted amount in the future, $d$ is the discount rate (as a fraction) and $n$ the number of years.

Alternatively, and taken into growth of capital on the annual basis in Eq. (3):

$$
X_{n}=X(1+i)^{n}
$$

This approach assumes the year is divided into $\mathrm{m}$ equal parts. The interest over the $\mathrm{m}$-th part of the year is $i / m$, again, without an $r v$. hence:

$$
\left.X_{n}=X\left(1+\frac{i}{m}\right)^{m n}\right)
$$

In this case, shown in Eq. (4), deriving Capital growth on a continuous basis unfortunately assumes no plough back of a residual value by letting $\mathrm{m}$ increase to infinity:

$$
X_{n}=X \lim _{m \rightarrow \infty}\left(1+\frac{i}{m}\right)=X \lim _{m \rightarrow \infty}\left\{\left(1+\frac{i}{m}\right)^{\frac{m}{i}}\right\}^{n i}=X e^{n i}
$$

This calculation erroneously only uses the mathematical function that: $\lim _{y \rightarrow \infty}(1+y)^{\frac{1}{y}}=e$, where $e=2.7183$. In this method, revenue is estimated by multiplying the oil and gas production forecast by the average market hub prices in the year received, irrespective of hydrocarbon quality (API gravity, sulphur content, etc.), and transportation expense (net back-cost) to deliver production to the market [13] does not project an informed and complete value bearing in mind, the omitted $r v$. Oil and gas prices are assumed constant throughout the field life cycle, and revenue from a field $f$, in year $t$, is computed as presented in Eq. (5) by:

$$
r(f, t)=q^{0}(f, t) p^{0}+q^{g}(f, t) p^{g},
$$

where the revenue forecast vector is given by:

$$
r(f)=r(f, 1), r(f, 2), \ldots)
$$

A net present value (NPV) also does not also infer that all discrete factors have been applied, but merely a summation discounted to a present worth, similar to other methods, such as, "Portfolio Theory" in taking economic decisions concerning investment options. In using this method in their research, [13] juxtaposes a probabilistic methodology to account for only known uncertainties and deployed an "efficient frontier" developed by Markowitz and some correlations coefficients to identify the best economic option. The NPV decision criterion is on the premise of maximized return on investment compared to other options, such that an investment is accepted or rejected if the NPV calculated is either positive or negative respectively [14]. As such some projects would have fallen below the economic huddle cutoff point without incomplete asset value and capital investment. However, a state of indifference is reached when the NPV is zero indicating that return on investment is the same as the alternative use, given the same discount rate and period, and it does not take into consideration the probabilistic properties of risks and opportunities, such as the residue values.

\section{PROBABILITY CONSIDERATIONS PIPELINES PROJECT ECONOMICS}

IN

Risks and uncertainties constraining robust investment decisions are considered in project economics on measured scales of probability distributions, using tools such as, expected value (EV) functions for probability (P) distribution in Eq. (6) as follows:

$$
E V=\sum_{I+1}^{N} x i P(x i)
$$

Notably, organizations are in business to make money, where the success or failure is measured by the profitability - a ratio of the income to the investment [15]. The profitability - a key business performance indicator practically gauges the return on investments [7, 16], and expressed mathematically in Eq. (7) as:

$$
\begin{aligned}
\text { Profit }= & \text { Oil Price } \times \text { Oil Rate } \\
& -(\text { CAPEX }+ \text { TAX }+ \text { ROYALTIES })(7)
\end{aligned}
$$

In principle, the ability of the capitalized infrastructure to technically and operationally meet the intended business objective, to the point of paying off the capital and operational investment within the designed operational duration, is a measure of an investment success. A derailment, or failure to sustain the project objective within the desired duration, is an indication of poor investment. Experience has shown that this cash-flow model has never accounted for or taken into consideration, a residual or realizable service value of the facilities, post the zero book values. This begs the question on how realistic are the usual book values posted by organizations, given this uncharted gray area? Interestingly, pipelines residual value (rv) is becoming a significant factor that should not be ignored in cash-flow analysis for different reasons, including; tumbling oil prices, increasing energy demands, investment decline coupled with natural production decline of oil fields, prompting organizations to seriously seek alternative ways to elongate the life of existing facilities, to sustain crude production and transportation [17]. The defining factor is at what point will the rv become useful to an investor in the investment decision process?

To etch a glimpse of the travails of this missing link, we consider [18] report on minimizing financial risks where they underscored the costs impact of endless reliability and availability challenges typical of challenges faced with aging pipeline facilities, notwithstanding organizational retain or rehabilitate policies. Considering actual life of pipeline facilities as near infinite in the cash-flow equation, would unmistakably fill a void, often but 
not, adequately needful for an imperative investment decision In principle, the ability of the capitalized infrastructure to technically and operationally meet the intended business objective, to the point of paying off the capital and operational investment within the designed operational duration, is a measure of an investment success. A derailment, or failure to sustain the project objective within the desired duration, is an indication of poor investment. Experience has shown that this cash-flow model has never accounted for or taken into consideration, a residual or realizable service value of the facilities, post the zero book values. This begs the question on how realistic are the usual book values posted by organizations, given this uncharted gray area? Interestingly, pipelines residual value (rv) is becoming a significant factor that should not be ignored in cash-flow analysis for different reasons, including; tumbling oil prices, increasing energy demands, investment decline coupled with natural production decline of oil fields, prompting organizations to seriously seek alternative ways to elongate the life of existing facilities, to sustain crude production and transportation [17]. The defining factor is at what point will the rv become useful to an investor in the investment decision process?

To etch a glimpse of the travails of this missing link, we consider [18] report on minimizing financial risks where they underscored the costs impact of endless reliability and availability challenges typical of challenges faced with aging pipeline facilities, notwithstanding organizational retain or rehabilitate policies. Considering actual life of pipeline facilities as near infinite in the cash-flow equation, would unmistakably fill a void, often but not, adequately needful for an imperative investment decision [19]. The financial benefit of $\mathrm{rv}$ in pipeline projects economics, laterally applied, could be quite substantial and a game changer $[20,21]$ including beneficial cost of retained facilities, avoidable development cost of replacement, level, and quality of inventory, and plant or field productivity.

\section{LIMITATIONS OF RETURN ON AVERAGE CAPITAL EMPLOYED (ROCE)}

ROCE as a historical capital productivity performance measure ratio is confined to earnings against invested capital. This approach though meant for long-term capital-intensive investments, is skewed without the cost of financing and other ancillary factors. To account for the alltime risks impact, the net cash-flow model should be adjusted with an effective risk factor that should account for always ignored service value beyond the 20-25 years economic life, which historically has been shown, in the case of pipelines for an additional 20 to 40 years. To calculate the risk adjusted return on capital (RAROC), banks use the ratio of the difference between the 50th percentile P50 or its median return, and the fifth percentile P5 return on a project to its standard deviation in Eq. (8) [22].

$$
\mathrm{RAROC}=P 50=\frac{P 5}{\delta}
$$

This approach is also not holistic as it naturally considers only the downward side, without considering the upward swing of uncertainties or risks. Since risks and uncertainties are time dependent, and evolve over time, a stochastic evaluation that highlights the risk trend over time is needed to provide veritable Investment Profitability (Under Uncertainty) or expected payoff and actual revenue represented Eq. (9) and Eq. (2) respectively.

\section{Expected Payoff}

\section{$=$ A Risk Adjusted Net Income}

$=\{($ Oil Price $\times$ Oil Production -

(Capital Expenditure (Capex)+

Operational expenditure (OPEX) + Cost of capital)

$\times$ inflation factor $\times$ escalation factor)

$-($ Tax + Royalties + Sign on bonus $)\}$

$\times$ Effective Risk Factor

$=$ Revenue (Risk adjusted Cash in)

-Investment Costs (Risk adjusted Cash out)

$$
\text { Revenue }=\text { Oil Price }(\mathrm{P}) \times \text { Oil Rate }(\mathrm{Q})
$$

Where the Oil Price per barrel $(\mathrm{bbl})=$ base price/bbl $+A\left({ }^{\circ} A P I\right)-B(\% \mathrm{~S})$, adjusted for viscosity and sour quality. The future oil base price generation is forecasted from historical oil price using the Time Series Forecasting Methodology.

\section{CONCLUSION/RECOMMENDATIONS}

The limitations posed by conventional approaches in cash-flow risk models, without factoring the full asset value, can be deduced from how they handle multi-criteria risk management issues of normalization, robustness, hedging, weighting, and probability distribution.

Criteria Weighting - Conventional approaches prefer normalization as a way of giving weight to the multi-variant criteria without reasonable objectivity. The deployment of Pareto principles [23] is often, in rare cases, considered too complex.

Hedging - Conventional approaches resort to hedging in decision making, due to more pressing factors such as for safety reasons, reliability, etc., with potential to trigger more investment lacking a uniquely defined process.

Normalization - Conventional methods adopt compromise solutions when faced with contradictory objectives, such as; minimizing losses and maximizing reliability or evaluating multicriteria with unrelated values, where the units for quantifying criteria and the values of the objective functions vary. The quality of the final solution becomes a product of subjective reasoning, which 
does not translate all values of objective function for all criteria, scenarios, and plans to discrete values.

Probability of scenarios - contributes one way or the other in determining the final solution. The scenarios with small probabilities are most times neglected by the conventional models in favour of end boundaries, forgetting that between these two end scenarios are all other possible scenarios.

Robustness - when faced with a group of options, conventional approaches go for the optimum plan for all criteria and scenarios with often maximal deviation from the best plan, with a risk of isolating even the best scenario. Sometimes, getting the solution requires iteration by gradually increasing the number of best plans for each scenario or gradually increasing maximal deviation percent, until there is a plan that is $100 \%$ robust. This raises a fundamental concern; what if the $100 \%$ plan is not robust, or there are more such plans?

The study successfully extricated a missing link with a huge potential to unlock the hidden real value of pipelines in projects' economics evaluation scheme. The findings developed a critically thought out element to systematically refine the cash-flow formula for an informed basis to optimize the investment decision. Thus, organizations would need to systematically:

- Establish a statistical data of pipelines total life at-service duration for all products.

- Establish the residual life of the respective pipelines after the generic economics duration.

- Redefine the cash-flow model to incorporate a booth strapping factor that ploughs back the residual value of pipelines in the profitability index.

- Ensure all future pipeline projects accounted for the residual values to ensure informed and realistic decisions.

\section{References}

[1] T. Husseini. (2020, February) Transporting oil and gas: the world's longest pipelines. [Online]. Available: https://www.offshore-technology.com/features/ worlds-longest-pipelines/

[2] J. Schuyler, Risk and Decision Analysis in Projects, 3rd ed. Project Management Institute, USA: Planning Press, October 2016.

[3] E. Schimmel, "Remaining life assessment using api 579," dynaflow Research Group Training Module.

[4] N. Shaik, S. Pedapati, and F. Abd Dzubir, "Remaining useful life prediction of crude oil pipeline by means of deterioration curves," Environmental Science, Process safety Progress, American Institute of Chemical Engineers, vol. 39, no. 1, pp. 56-75, 2020.

[5] Y. Feng, Y. Yang, and B. Huang, "Corrosion analysis and remaining useful life prediction for storage tank bottom," Tsinghua University, Beijing, vol. 16, no. 5, pp. $112-117,2019$.

[6] Z. Zangenehmadar and O. Moselhi, "Assessment of remaining useful life of pipelines using different artificial neural networks models," Journal of Performance of Constructed Facilities, vol. 30, no. 5, pp. 843-849, 2016.
[7] Z. Weiguo, L. Dongjing, W. Hai, and P. Xinxin, "Remaining-life prediction and reliability assessment of buried gas pipelines under corrosion and alternating loads," Journal of Pipeline Systems Engineering and Practice, vol. 6, no. 1, pp. 216-220, 2015.

[8] C. Alaneme and A. Igboanugo, "Managing marginal oilfield risks with fuzzy logic and monte carlo simulation for economics optimization," Journal of Emerging Trends in Engineering and Applied Sciences, vol. 3, no. 4, pp. 660-667, 2012.

[9] C. Alaneme, "A factorial study on the inherent risks of nigeria marginal oilfields," Research Journal of Applied Sciences, vol. 6, no. 3, pp. 468-476, 2013.

[10] T. Adams, J. Albers, J.A. amd Lund, and M. Back, "Portfolio management for strategic growth," Oilfield Review, vol. 12 , no. 4, pp. 10-11, 2000.

[11] S. J.R. and Nieman, Risk and Decision Analysis in Projects, 2nd ed. Pennsylvania: Project Management institute, 2009.

[12] M. Nederlof, "Consultancy, software and education for oil and gas exploration," The Hague: Chamber of Commerce, May 2011.

[13] P. Bastos and E. Bortoni, "Portfolio analysis applied to small hydroelectric plant investment," in 8th International Conference on Probabilistic Methods Applied to Power Systems, Iowa, 2004, pp. 12-16.

[14] A. Mian, "Project economics and decision analysis," Deterministic models PennWell Corporation, vol. 1, no. 2, pp. 217-228, 2010.

[15] G. Heerkens, "In praise of roi, pm network," Project Management Institute, vol. 24, no. 5, p. 23, 2010.

[16] E. Goldratt and J. Cox, The Goal: A Process of Ongoing Improvement, 2nd ed. North River Press, 1984.

[17] M. Kaiser and Y. Yu, "Marginal production in the gulf of mexico - ii. model results," Applied Energy Journal, vol. 67 , no. 8, pp. 2526-2534, 2010.

[18] T. Baustad, G. Courtin, T. Davies, R. Kenison, J. Turnbull, B. Gray, Y. Jalali, J. Remondet, L. Hjelmsmark, T. Oldfield, C. Romano, R. Saier, and G. Rannestad, "Cutting risk, boosting cash flow and developing marginal fields," Oilfield Review, vol. 8, no. 4, pp. 1831, 1996.

[19] U. Chinbat and S. Takakuwa, "Using operation process simulation for a six sigma project of mining and iron production factory," in Institute of Electrical and Electronics Engineers publications, Winter Simulation Conference Proceedings, New Jersey, 2008, pp. 2431-2438.

[20] S. Morbey, "Offshore brazil: Analysis of a successful strategy for reserve and production growth," Norwegian Petroleum Society Special Publications, vol. 6, no. 1, pp. 123-133, 1996.

[21] T. Kråkenes and A. Roxar, "Reducing uncertainty in reservoir management," Zeus Technology magazine, vol. 4 , no. 1 , p. 11,2009 .

[22] M. Hendriks, J. De Boer, A. Smilde, and D. Doombos, "Multi-criteria decision making," Chemomertics and Intelligent Laboratory Systems, vol. 16, no. 6, pp. 175-191, 1992.

[23] V. Pareto, "Course of political economics (cours d'economie politque). beyond disciplinary boundaries," University of Southampton, vol. 1, no. 11, pp. 1322$1348,1986$. 